\title{
The Effect of Oxygen Exposure on Erythrocyte Phospholipid Composition
}

\author{
Masao Abe* and Alex Sevanian $\dagger$ \\ Department of Medicine, School of Medicine University of \\ California, Los Angeles, California 90024
}

\begin{abstract}
Abe, M. and Sevanian, A. The Effect of Oxygen Exposure on Erythrocyte Phospholipid Composition. Tohoku J. exp. Med., 1981, 135 (2), 205-211 Phospholipids in plasma and erythrocytes of rats exposed to $100 \%$ oxygen for 3 days were analyzed. Exposed rats contained lower quantities of several phospholipids in both plasma and erythrocytes than in matched controls. Pronounced decreases were found in phosphatidylcholine and lysophosphatidylcholine. The proportion of disaturated species in erythrocyte phosphatidylcholine was significantly greater after oxygen exposure. There was an increase in percentage of saturated fatty acids with a proportionate decrease in percentage of unsaturated fatty acids. The increase in saturation was associated primarily with palmitate while decreased unsaturation involved primarily linoleic acid. In plasma the proportions of stearic acid increased while those of linoleic, arachidonic and docosahexaenoic acids decreased in phosphatidylcholine. Damage to cell lipids may account for increased hemolysis which occurs after exposure to high oxygen concentrations. Erythrocytes recovered following oxygen exposure contained phospholipid species commonly found in immature red blood cells. oxygen toxicity; erythrocyte and plasma phospholipids; phosphatidylcholine
\end{abstract}

Changes in erythrocyte populations after exposure to high concentrations of oxygen have been widely studied using numerous animal species as well as man. Among the best described alterations resulting from oxygen exposure are the changes in hematocrit (Kann et al. 1967; Mickel et al. 1975), and increased hemolysis (Mengel et al. 1964a; Zirkle et al. 1965; Kann et al. 1967). Effects such as these may be related to altered membrane structures which are largely composed of lipids, especially phosphatidylcholine. Altered membrane structure or function may result by affecting certain enzymes located in the membrane which require discrete interactions with specific phospholipids (Wallach 1972; Roelofsen and van Deenen 1973). Furthermore, changes in the fatty acid composition of such phospholipids can affect membrane functions related to permeability and transport (van Deenen and De Gier 1964; Deuticke and Gruber 1970; Wessels and Veerkamp 1973).

Damage to erythrocytes during hyperoxia is believed to occur through the

Received for publication, February 25, 1981.

* Present address: Department of Biochemistry, Sapporo Medical College, Sapporo 060.

$\uparrow$ Present address: Laboratory of Nuclear Medicine and Radiation Biology, University of California, Los Angeles, California 90024. 
peroxidation of unsaturated lipids (Mengel et al. 1974b). This process may occur non-enzymatically in the presence of ferrous ion, and has been well described (Mead 1976). The peroxidation of red cell lipids in vivo and the relationship to hemolysis was described by Mengel in both animals (Mengel and Kann 1966) and man (Mengel and Kann 1965). For this reason we studied the effects of oxygen exposure on the content of the major erythrocyte phospholipids as well as changes which occur in plasma.

\section{Materials and Methods}

Young male rats (specific pathogen free) were obtained from Hilltop Labs and used within three days of delivery. Twenty rats were randomly selected and placed into stainless steel cages which were placed into an exposure chamber identical to those used by Hinners et al. (1968) and exposed to $100 \%$ oxygen for three days. Oxygen concentrations were measured every eight hr using a Beckman oxygen analyzer. Control rats were allowed to breathe filtered air for three days and were otherwise treated identically to the experimental group. Food (Purina Rat Chow) and water were provided ad libitum. The rats were previously raised on a diet of Wayne Lab Blocks (Allied Mills, Ill). After the completion of the third day the animals were anesthetized with sodium pentobarbital, the chest was opened prior to the cessation of heart beat and blood collected into heparinized syringes by cardiac puncture. Blood samples were centrifuged at $500 \times \mathrm{g}$ for $10 \mathrm{~min}$ and washed twice with 3 volumes cold normal saline. The buffy was removed and plasma and erythrocyte fractions were separated for analysis. Aliquots of the plasma or erythrocytes fractions were used for the determination of protein content (Lowry et al. 1951), phospholipid content and measurement of major phospholipid classes. Lipids were extracted from erythrocytes using initially $5 \mathrm{ml}$ of methanol per 1 to $2 \mathrm{ml}$ of packed cells. This was followed by $5 \mathrm{ml}$ of chloroform-methanol $(1: 2, \mathrm{~V} / \mathrm{V}), 5 \mathrm{ml}$ chloroformmethanol $(2: 1, \mathrm{~V} / \mathrm{V})$ and $15 \mathrm{ml}$ chloroform. These extracts were pooled, evaporated under nitrogen and washed by a modification of the Folch procedure (Folch et al.1957). Plasma lipids were extracted by the method of Bligh and Dyer (1959). The various phospholipids were fractionated on silica gel-H coated plates using chloroform-methanol-water $(65: 25: 4, \mathrm{~V} / \mathrm{V} / \mathrm{V})$ as the developing solvent. The phospholipids were visualized under ultraviolet light by spraying the plates with $0.1 \% 2^{\prime}, 7^{\prime}$-dichlorofluorescein in ethanol. The individual phospholipids were then scraped from the plate and eluted from the silica gel by the method of Arvidson (1968). The fatty acid composition of phosphatidylcholine was determined by gas chromatographic analysis of the fatty acid methyl esters derived by methanolysis in an instrument, Perkin Elmer model 801, fitted with a column packed with 12\% DEGS (Supelco, Bellefonte, Penn). In addition, aliquots of blood were diluted in saline for cell counting using a standard hemocytometer. Hemoglobin content was measured according to the method of Austin and Drabkin (1935), and the remaining packed red blood cells were lyophilized at $-30^{\circ} \mathrm{C}$ for a dry weight determination. Saturated phosphatidylcholine was prepared from the isolated phosphatidylcholine by the method of Shimojo et al. (1974). The content of phospholipids was determined by the method of Bartlett (1959) and measurements calculated on the basis of $10^{8}$ cells or per $\mathrm{ml}$ of blood.

\section{RESUlts}

Rats exposed to $100 \%$ oxygen for 3 days displayed the following evidence of oxygen toxicity.

(1) The exposed animals had a significantly decreased body weight, being $195.1 \pm 4.2 \mathrm{~g}$ before exposure and $174.4 \pm 4.2 \mathrm{~g}$ after exposure $(p<0.001)$. Control rats gained weight during this period from $196.0 \pm 3.9 \mathrm{~g}$ to $218 \pm 5.7 \mathrm{~g}$. This may 
be attributed to lower food and water consumption in the exposed group.

(2) Twenty percent of the experimental rats died by the end of the third day, all dying within the last $24 \mathrm{hr}$. There was also a significant increase in plasma protein content in the exposed group as shown in Table 1.

Hemoglobin content remained unchanged, being $161.7 \pm 27.17$ for controls and $190.2 \pm 32.90$ for the experimental group (expressed as $\mathrm{mg} / \mathrm{ml}$ whole blood), and $3.37 \pm 0.90$ vs. $3.46 \pm 0.81$ (expressed as $\mathrm{mg} / 10^{8}$ cells).

No significant differences were seen in cell number $\left(\times 10^{8}\right.$ per $\left.\mathrm{ml}\right), 52.8 \pm 14.0$ vs. $63.9 \pm 8.98$ or in dry weight $\left(\mathrm{mg} / 10^{8}\right.$ cells $), 2.92 \pm 0.600$ vs. $3.42 \pm 1.012$. The content of protein and phospholipids in plasma of control and exposed rats are shown in Table 1.

The amount of total phospholipids in plasma were unchanged although there was a significant decrease in the amount of phosphatidylethanolamine, lysophosphatidylcholine and phosphatidylcholine. The erythrocytes exhibited a number of changes similar to those in plasma (Table 2). In this case the amounts of total cell phospholipids were lower. The only phospholipid (of those analyzed under these experimental conditions) that remained unchanged was sphingomyelin. Furthermore, about $26 \%$ of the phosphatidylcholine was saturated species. The purity of the saturated phosphatidylcholine prepared from erythrocytes was checked by gas chromatography and was found to be better than $95 \%$. The percentage of saturated phosphatidylcholine was found to increase with a proportional decrease

TABLE 1. Protein and phospholipid content in plasma of control and experimental rats

\begin{tabular}{lccc}
\hline & Control $(n)$ & Experimental $(n)$ & $n$ \\
\hline Protein $(\mathrm{mg} / \mathrm{ml})$ & $61.3 \pm 4.0(20)$ & $68.4 \pm 2.6(8)$ & $<.001$ \\
Phospholipid $(\mu$ moles $/ \mathrm{ml})$ & $2.29 \pm 0.20(10)$ & $2.32 \pm 0.16(8)$ & $\mathrm{NS}$ \\
Phosphatidylethanolamine & $0.07 \pm 0.01(10)$ & $0.05 \pm 0.01(8)$ & $<.001$ \\
Sphingomyelin & $0.26 \pm 0.02(10)$ & $0.29 \pm 0.03(8)$ & $\mathrm{NS}$ \\
Lysophosphatidylcholine & $0.44 \pm 0.03(10)$ & $0.27 \pm 0.02(8)$ & $<.001$ \\
Phosphatidylcholine & $1.44 \pm 0.15(10)$ & $1.27 \pm 0.11(8)$ & $<.02$ \\
\hline
\end{tabular}

Each value is expressed as means \pm s.D. NS, not significant.

TABLE 2. Protein and phospholipid content in erythrocytes of control and experimental rats

\begin{tabular}{lrrc}
\hline & Control $(n)$ & Experimental $(n)$ & $p$ \\
\hline Protein $\left(\mathrm{mg} / \mathbf{1 0} \mathbf{0}^{8}\right.$ cells) & $3.36 \pm 0.39(20)$ & $3.49 \pm 0.31(8)$ & $\mathrm{NS}$ \\
Phospholipid (nmoles $/ \times 10^{8}$ cells) & $46.2 \pm 7.8(16)$ & $39.3 \pm 4.2(16)$ & $<.01$ \\
Phosphatidylethanolamine & $11.0 \pm 2.1(16)$ & $8.5 \pm 1.8(16)$ & $<.01$ \\
Sphingomyelin & $9.9 \pm 1.7(16)$ & $9.2 \pm 1.6(16)$ & $\mathrm{NS}$ \\
Lysophosphatidylcholine & $1.9 \pm 0.5(16)$ & $1.4 \pm 0.3(16)$ & $<.001$ \\
Phosphatidylcholine (PC) & $20.4 \pm 3.8(16)$ & $16.4 \pm 1.3(16)$ & $<.001$ \\
Saturated-PC* & $26.6 \pm 2.4(16)$ & $28.5 \pm 2.2(16)$ & $<.05$ \\
Unsaturated-PC* & $73.4 \pm 2.4(16)$ & $71.5 \pm 2.2(16)$ & $<.05$ \\
\hline
\end{tabular}

Each value is expressed as means \pm s.D. NS, not significant.

* percentage to $\mathrm{PC}$. 
TABLE 3. Fatty acid composition of phosphatidylcholine in plasma of control and experimental rats (weight \%)

\begin{tabular}{cccc}
\hline Fatty acid & Control $(n=10)$ & Experimental $(n=8)$ & $p$ \\
\hline $16: 0$ & $29.3 \pm 2.6$ & $25.9 \pm 3.8$ & $\mathrm{NS}$ \\
$18: 0$ & $19.1 \pm 3.0$ & $27.0 \pm 1.8$ & $<.001$ \\
$18: 1$ & $5.8 \pm 1.1$ & $5.6 \pm 1.0$ & $\mathrm{NS}$ \\
$18: 2$ & $25.4 \pm 4.6$ & $19.6 \pm 2.0$ & $<.01$ \\
$20: 4$ & $15.1 \pm 2.4$ & $20.0 \pm 3.1$ & $<.01$ \\
$22: 6$ & $5.2 \pm 2.2$ & $1.9 \pm 0.4$ & $<.001$ \\
Saturation & $48.4 \pm 2.4$ & $52.9 \pm 2.7$ & $<.01$ \\
\hline
\end{tabular}

Each value is expressed as mean \pm s.D. NS, not significant.

TABLE 4. Fatty acid composition of phosphatidylcholine in erythrocytes of control and experimental rats (weight \%)

\begin{tabular}{cccc}
\hline Fatty acid & Control $(n=16)$ & Experimental $(n=16)$ & $p$ \\
\hline $16: 0$ & $45.2 \pm 4.5$ & $49.7 \pm 4.4$ & $<.02$ \\
$18: 0$ & $16.7 \pm 2.0$ & $17.4 \pm 3.3$ & $\mathrm{NS}$ \\
$18: 1$ & $12.6 \pm 2.6$ & $11.7 \pm 2.2$ & $\mathrm{NS}$ \\
$18: 2$ & $19.7 \pm 3.8$ & $14.9 \pm 2.0$ & $<.001$ \\
$20: 4$ & $5.9 \pm 2.3$ & $6.2 \pm 2.3$ & $\mathrm{NS}$ \\
$22: 6$ & trace & trace & \\
Saturation & $61.9 \pm 4.2$ & $67.0 \pm 2.7$ & $<.01$ \\
\hline
\end{tabular}

Each value is expressed as mean \pm s.D. NS, not significant; trace, less than $1 \%$.

in unsaturated phosphatidylcholine after $\mathrm{O}_{2}$ exposure.

The proportions of fatty acids found in plasma and erythrocyte phosphatidylcholine are shown in Tables 3 and 4, respectively. Again the proportions of saturated fatty acids were found to increase in the both fractions after $\mathrm{O}_{2}$ exposure. In the plasma, this increase was primarily due to stearic acid. The decreases were seen in linoleic and docosahexaenoic acids. These tables indicate only the major fatty acids present in phosphatidylcholine and those in which changes were observed. An increase was also noted for arachidonic acid, but only in the plasma fraction. In the erythrocyte, the increase in saturated fatty acids was accounted for by palmitate accompanied by a decrease in linoleate.

\section{Discussion}

Under the conditions of this experiment the rats displayed severe reactions after three days of exposure to oxygen. Consumptions of food and water were markedly reduced resulting in a weight loss much like that seen in fasted animals.

Red cells destruction is believed to occur at an increased rate after high oxygen exposure (Mengel et al. 1964a) and although levels of hemolysis were not directly measured, no changes were found in hemoglobin content. We chose not to measure hematocrit from these animals preferring rather to use gentle centrifugation to 
separate erythrocytes from plasma thus improving the reliability of our chemical analyses. The discrepancy between the data for cell number and dry weight per cell is probably due to a loss in red cell mass as previously reported (Mickel et al. 1975). This may in part be accounted for by dehydration. The increase in protein content per ml of plasma may also be attributed to dehydration. Since no attempt was made to separate red blood cells of various ages from chemical analysis, we could not directly account for changes in phospholipids within red cell subpopulations. However, the data presented do suggest that the relative numbers of "immature" cells increased, based on known differences of lipid composition in red blood cells of different ages (van Deenen and De Gier 1974). During aging a minor relative increase occurs in phosphatidylcholine. This is accompanied by an increase in linoleate, compensated by a decrease in arachidonate and other long chain acids. The reticulocyte as delivered from the marrow is deficient in linoleate, and the circulating cell is able to accumulate linoleate by acylation and exchange processes. Low concentrations of linoleate are characteristic of pathological erythrocyte populations with increased numbers of young cells (van Deenen and De Gier 1974).

Phosphatidylcholine typically comprises about $40 \%$ of the phospholipids in erythrocytes, and is the largest single lipid component of the membrane (van Deenen and De Gier 1974). Large changes in its content or in the relative proportions of the saturated or unsaturated species would be expected to alter membrane dynamics. In this case the relative increase in saturated phosphatidylcholine and decrease in unsaturated phosphatidylcholine might be a contributing factor in cell fragility. These changes occur primarily through the increases in palmitic acid content and decrease in linoleic acid. During normal red cell maturation the content of linoleic acid increases markedly accompanied by a proportional decrease in palmitic and arachidonic acids (Phillips et al. 1969). This process is presumed to occur through a progressive deacylation-reacylation of phosphatidylcholine in the erythrocyte, utilizing linoleic acid or cholesteryl linoleate in the plasma (van Deenen and De Gier 1974). The decreased proportion of linoleic acid found in erythrocyte phosphatidylcholine probably results from the lowered levels in the plasma yielding a red cell population with immature cell characteristics. The diminished intake of food could be a factor in lowering the levels of this essential fatty acid.

Another factor which may contribute to the linoleic acid deficiency in phospholipids is the lower concentrations of lysophosphatidylcholine in both plasma and erythrocytes of oxygen exposed rats. This may arise from the inhibition of plasma lecithin-cholesterol acyltransferase (LCAT) reaction by oxygen (Mickel et al 1975) or by lipid hydroperoxides (Mengel et al. 1964b; Glomset 1968). A decrease in LCAT has been associated with reduced plasma cholesteryl ester concentrations and with anemia following exposure to pure oxygen (Mickel et al. 1975).

Although we did not determine the quantity of cholesterol esters, a report indicats that their levels are also diminished following lipid peroxidation (Takatori 
and Privett 1974). It is likely that the proportions of young red blood cells increased after 3 days of exposure to $100 \%$ oxygen. This may be due either to lysis of older cells which contain more oxidizable lipids, or that the stress released young cells from the marrow. Finally, a decreased availability of essential fatty acids, e.g., linoleic acid, would reduce reacylation of erythrocyte phosphatidylcholine, giving rise to a population of cells deficient in this fatty acid and resembling red cells of an immature character.

\section{References}

1) Arvidson, G.A.E. (1968) Structural and metabolic heterogeneity of rat liver glycerophosphatides. Europ. J. Biochem., 4, 478-486.

2) Austin, J.H. \& Drabkin, D.L. (1935) Spectrophotometric studies. III. Methemoglobin. J. biol. Chem., 112, 67-88.

3) Bartlett, G.R. (1959) Phosphorous assay in column chromatography. J. biol. Chem., 234, 466-468.

4) Bligh, E.G. \& Dyer, W.J. (1959) A rapid method of total lipid extraction and purification. Canad. J. Biochem. Physiol., 37, 911-917.

5) Deuticke, B. \& Gruber, W. (1970) Anion permeability of mammalian red blood cells: Possible relation to membrane phospholipid patterns. Biochim. biophys. Acta, 211, 369.

6) Folch, J., Lees, M. \& Sloane-Stanley, G.H. (1957) A simple method for the isolation and purification of total lipids from animal tissues. J. biol. Chem., 227, 497-499.

7) Glomset, J.A. (1968) The plasma lecithin: cholesterol acyltransferase reaction. $J$. Lipid Res., 9, 155-167

8) Hinners, R.G., Burkart, J.K. \& Punte, C.L. (1968) Animal inhalation exposure chambers. Arch. environm. Hlth, 16, 194-206.

9) Kann, H.E., Mengel, C.E., Clancy, W.T. \& Timms, R. (1967) Effects of in vivo hyperoxia on erythrocytes. VI. Hemolysis occurring after exposure to oxygen under high pressure. J. Lab. clin. Med., 70, 150-157.

10) Lowry, O.H., Rosebrough, N.J., Farr, A.L. \& Randall, R.J. (1951) Protein measurement with the Folin-phenol reagent. J. biol. Chem., 193, 265-275.

11) Mead, J.F. (1976) In: Free Radicals in Biology, edited by W.A. Pryor, Academic Press, N.Y., pp. 51-68.

12) Mengel, C.E. \& Kann, H.F. (1965) Effects of in vivo hyperoxia on erythrocytes. II. Hemolysis in a human after exposure to oxygen under high pressure. Blood, 25, 822829.

13) Mengel, C.E. \& Kann, H.F. (1966) Effects of in vivo hyperoxia on erythrocytes. III. In vivo peroxidation of erythrocyte lipids. J. clin. Invest., 45, 1150-1158.

14) Mengel, C.E., Kann, H.E. \& Horton, B.D. (1964a) Studies of the hemolytic effect of in vivo hyperoxia. Clin. Res., 12, 60-65.

15) Mengel, C.E., Kann, H.E., Lewis, A.M. \& Horton, B.D. (1964b) Mechanisms of in vivo hemolysis induced by hyperoxia. Aerospace Med., 35, 857-861.

16) Mickel, H.S., Foulds, E.L., Clark, D.A. \& Larkin, E.C. (1975) Effects of pure oxygen atmosphere in vivo on plasma lecithin-cholesterol acyltransferase reaction. Lipids, 10, 740-744.

17) Phillips, C.B., Dodge, J.T. \& Howe, C. (1969) The effect of aging of human red cells in vivo on their fatty acid composition. Lipids, 4, 544-549.

18) Roelofsen, B. \& van Deenen, L.L.M. (1973) Lipid requirement of membrane-bound ATPase: Studies on human erythrocyte ghosts, Europ. J. Biochem., 40, 245-257.

19) Shimojo, T., Abe, M. \& Ohta, M. (1974) A method for determination of saturated phosphatidylcholine. J. Lipid Res., 15, 525-527.

20) Takatori, T. \& Privett, O.S. (1974) Studies of serum-lecithin-cholesterol acyl 
transferase activity in rat: Effect of vitamin E deficiency, oxidized dietary fat, or intravenous administration of ozonides or hydroperoxides. Lipids, 9, 1018-1023.

21) van Deenen, L.L.M. \& De Gier, J. (1964) Lipid of cell membrane. In: The Red Blood Cell, edited by C. Bishop \& D.M. Surgenor, Academic Press, N.Y., p. 243.

22) van Deenen, L.L.M. \& De Gier, J. (1974) Lipids of the red cell membrane. In: The Blood Cell. edited by D.M. Surgenor, Academic Press, N.Y. pp. 147-211.

23) Wallach, D.F.H. (1972) The dispositions of proteins in the plasma membranes of animal cells: Analytical approaches using controlled peptidolysis and protein labels Biochim. biophys. Acta, 265, 61-83.

24) Wessels, J.M.C. \& Veerkamp, J.H. (1973) Some aspects of the osmotic lysis of erythrocytes: III. Comparison from eight mammalian species of glycerol permeability and lipid composition of red cell membrane. Biochim. biophys. Acta, 291, 190-196.

25) Zirkle, L.G., Mengel, C.E., Butler, S.A. \& Fuson, R. (1965) Effects of in vivo hyperoxia on erythrocytes. IV. Studies in dogs exposed to hyperbaric oxygen. Proc. Soc. exp. Biol., 119, 833-838. 